\title{
Use of Digital Objects of Programming (DLO) for the Teaching in Educational Institutions - Riohacha, Colombia
}

\author{
Eíder J. Mejía Guerra ${ }^{1 *}$, Iris A. Jiménez Pitré2 and Geomar Molina Bolívar² \\ IIndependent Researcher Magisterium of Colombia, Columbia; eidermejiag@gmail.com \\ ²BIEMARC Research Group, University of La Guajira, Riohacha, Colombia; \\ iajimenez@uniguajira.edu.co,gmolina@uniguajira.edu.co
}

\begin{abstract}
Objective: Information and Communication Technologies (ICTS) are part of the world of our students; it would be interesting for the teaching staff to opt for the use of versatile tools, such as Digital Learning Objects (DLO), which was raised to characterize the use of DLOfor the teaching of mathematics in the educational institution School Denzil Riohacha City in Colombia. Materials and Methods: An investigation was conducted not experimental field and cross-sectional, in a total of 40 teachers belonging to the educational institution, by means of surveys, which provided information on the characteristics, components, and types of DLO, using a categorization system (Suitable, Moderately suitable, appropriate and inappropriate). Finding: The results indicate that, in terms of the three dimensions studied, all of which are available in the appropriate category, finding that teachers recognize all aspects related to the DLO. Applications: It is concluded that the structure and use of DLO in the educational institution, is adequate School Denzil, however, there are strategies to optimize the use of these tools, especially the use of this instrument, to follow up on this aspect in the educational institutions in Colombia.
\end{abstract}

Keywords: Digital Learning Objects (DLO), Educational Institutions, Education, Information and Communication Technology (ICT).

\section{Introduction}

Today's society demands new skills to all people not to be converted into digital illiterate, emphasizing that society must act from various segments in order to fulfil this task, being the school who will continue to face the greatest challenge: To ensure that all young people to acquire an adequate basic training, in which, as always, the math skills constitute one of the most important centers ${ }^{1}$. There is no doubt that Information and Communication Technologies (ICTS) are part of the world of our students, so that it would be interesting for the teachers to opt for the use of versatile tools, that is, those that allow for the game of reflection on practice and stimulate the re-thinking of the models of teaching and learning ${ }^{2}$. As a result, there is a need to seek other didactic strategies that contribute to the development and strengthening of mathematical skills of our students, in accordance with the prodigious progress in technology and in an attempt to obtain significant learning.

At the same time, ICTs are the result of changes sprouts from the industrial revolution and the accelerated scientific and technological advancement that experience humanity, which resulted in transformations in all areas. Because of this, there are new habits; dysfunctions in people by instituting a new social class at the global level might be called the society of information and knowledge. In short, one of the problems facing education systems worldwideis the formation of individuals able to respond to new challenges in the field professional, scientific, technical, technological and educational to transform an active and creative reality for the benefit of humanity.

*Author for correspondence 
On the other hand, currently are larger and more complex in the claims presented to it at the educational units in the pedagogical, linked to the formation of student's proficient to deal with the obsolete and current traditional paradigm of teaching that still maintains its legacy in most educational institutions at the international level.

In the meantime, today and with the rise of ICT, has led to the emergence of a number of applications, tools and resources that enable you to innovate in the classroom. One of these resources is the virtual objects of learning, which becomes a bridge of teaching and learning between teachers and students in a didactic and different. In response to these considerations, one of the technological resources that has gained greater strength in the work of the classroom are Digital Learning Objects (DLO), which are defined as computerized programs (digital) used didactically in the teaching and learning process $s^{3}$. However, it will only be a digital resource that supports this process, in the same way his creation must be governed by methodologies that ensure the contents and their distribution. To be placed in North America, the United States has made effortsto ensure that at the University of Colorado Boulder evaluate virtual objects of learning such as PHET which is an acronymfor Physics Education Technology, which isan ongoing effort to provide an extensive set of simulations to improve the way in which the natural sciences are learned and taught. The Americans carry the banner of evaluators of DLO tools for example have companies dedicated as LORI (Learning Object Review Instrument), and Merlot (Multimedia Educational Resource for Learning and Online Teaching).

To be placed on the Central American context some authors claim that a problem facing the Assessment of Learning Objects (OA), is the fact that you don't have a team of specialists to ensure the quality of the final product andat eachstage of development, which is due to the different contexts of application for which an OA can be developed ${ }^{4}$. It is necessary to have the support of specialists or quality publishers in order to ensure the veracity of the content and the relevance of the resources used for each of these contexts ${ }^{5}$. At the same timeinMexico, "the evaluation of the DLO is an important element that impacts, both in design, as in the understanding of their utilitarian values in the processes of instruction and learning support. They are very various factors to consider" $\underline{6}$.

In that connection, in order to obtain the required levels there are models and standards that help to establish the quality system for the evaluation of DLO, the Chileans use systems such as Lori (Learning Object Review Instrument) and Merlot (Multimedia Educational Resource For Learning and Online Teaching), which is the only repository that performs an evaluation of the quality of learning objects that stores and provides a list of the ranking of the evaluated objects.

In the same order of ideas, in the Bolivarian Republic of Venezuela was initiated from 2004 a set of actions where brings the benefits of ICTS to achieve greater efficiency in the learning processes ${ }^{ }$; Without doubt, Colombia could not be oblivious to the use of virtual objects for learning in the educational system, therefore, the Ministry of National Education (MEN) in the year 2011, made the first call for virtual objects through their virtual portal Colombia Aprende, where assessment strategies, where stand out from pedagogy (capacity of motivation, reusability, potentiality of the teaching resource, promotion of the initiative and self-learning), didactic curriculum, (today and content accuracy, usefulness, consistency of the didactic proposal, the content lacks of negative messages), and other aspects ranging from the technical to the functional aesthetic.

Such is the case that in the Department of La Guajira, more precisely in its capital Riohacha, The School Educational Institution Denzil does not have a system of evaluation of virtual objects that allow them to have sufficient confidence, sothat you can bring to a significant learning, particularly in core subjectssuch asmath,where it has been noted according totheevidence to know and Pisa inthe year 2013, Colombia is the last posts inthis area of theexact sciences. In the institutionof primary and secondary education school "Denzil Escolar"; these problems may be referred to the lack of evaluation and utilization of digital objects of programming, apathy or fear to the use of the acquired technology, low knowledge of ICT by teachers, neglect as a tool the imparting of the understanding of knowledge; but, above all, its lack of implementation and knowing how to choose on the part of teachers a tool able to give you an DLO different learning and meaningful to students.

It should be noted that the possible causes of these symptoms, visible to the naked eye, it may be due to poor teacher training,onthe choice and general useand didacticof digital objects of learning for its implementation in the classroom, as well as the resistance presented by the teachers before the didactic and methodological change which requires the use of DLO in the classroom, 
which entails conserve preferably the traditional patterns of conventional education, which does not allow you to optimize the learning progress of students nor the fulfilment of Instructional Objectives ${ }^{4}$. It is important to mention the theoretical aspects that served as the basis for the present investigation, such as the characteristics of the DLO ${ }^{8}$,Agreed by the scientific community, which are accessibility, reusability and interoperability; as well as distinguish the components that make them up about it, in the first instance highlights the information units, content and didactic as the main axes on which to build the entire structure of the object" ${ }^{9}$ And finally, welcome thetypesofOAthat categorizes in fundamental, combination closed, open, generative combination presentation and generative instructional design ${ }^{10}$.

With this study it will be possible to propose to the Colombian teachers, new alternatives to choose an ode of mathematicsandintegrate it in personal and professional life, so that they can cope with the demandsoftheir affective and cognitive performance areas, so as to improve thelowlevel students have in the area of mathematics. In view of the foregoing was raised as an objective tocharacterize the use of Digital Learning Objects for teaching mathematics through an instrument apt, in the educational institution School Denzil Riohacha City in Colombia. In this way, contribute to what you're looking for the Ministry of Education inColombiaon the quality policy and that hasdriven projectsthat involve the use of the DLO's and electronic media in pedagogical practices for teachers. Thus, with a view to improving the development of the competences of the Colombian students when it comes to thoughts of mathematicians, and, above all, to the strengthening of skills and competencies for teachers in the effective use of these resources.

\section{Materials and Methods}

An investigation was carried out non-experimental field and cross-sectional study. Considering that the study population is relatively small, it became necessary to take the data of the totality, by which to 40 teachers belonging to the school educational institution Denzil in the city of Riohacha in Colombia, distributed in the main venue (20 Hemlock (teachers), 10 teachers), and Taguaira (10 teachers), surveys were applied, so as to interpret the information collected on the site of the events ${ }^{11}$. The instrument used consisted of a questionnaire of 33 items or structured questions, about the characteristics (accessibility, interoperability, reuse), Components (a unit of information, content Unit, didactic unit) and types (Fundamental, Combination closed, open, generative Combination Presentation, generative institutional) of DLO,with the option to be answered with four (4) alternatives such as: Always, Almost always, almost never, and never, never with a value of 4, 3,2 and 1 respectively, thus applying the Likert scale $\frac{11}{}$, Which made it possible to categorize the responses by means of a sphere of values, specifically: Suitable (3.26-4), moderately suitable (2.51-3.25), ill-suited (1.76-2.50) and inadequate (1-1.75). Developed a format of validation for the implementation of the instrument, which included the instructions guide to the experts, in addition it was found its reliability through the formula Cronbach's alpha $(\mathrm{rtt}=0.95)$, through a pilot test $\underline{11}$. To complete the investigative process was carried out the data analysis Data were analyzed using descriptive statistics, specifically the absolute and relative frequencies, as well as the averages to obtain definitely the category, for thisis employment the SPSS 22.

\section{Results and Discussion}

For the analysis and discussion of the results taking into account the following aspects.

\subsection{Characteristics of the DLO}

Table 1 shows the distribution of frequencies of the characteristics of the DLO, where it can be observed that for the indicator Accessibility, the 80 per cent of respondents answered that the documents are stored internally in the DLO, are sought out easily by students and the files are tagged with descriptive information, while the $20 \%$ responded almost always, obtaining an arithmetic mean for this indicator of 3.49 (adequate). This trend corresponds to the theoretical postulates (5), Thanks to the labelling through various descriptors (metadata) would enable the cataloguing and storage in the corresponding repository.

With regard to the indicator Interoperability, it can be seen that the $98 \%$ of subjects surveyed responded that they always exchange information through industrystandard platforms such as Windows and Linux, learning objects are transferred without drawbacks and are used with different technologies. While only $2 \%$ responded 
Table 1. Frequency distribution of the dimension characteristics of DLO

\begin{tabular}{|c|c|c|c|c|c|c|c|}
\hline \multirow{2}{*}{ Indicator } & \multirow{2}{*}{$\begin{array}{c}\text { Always } \\
\text { N (\%) }\end{array}$} & \multirow{2}{*}{$\begin{array}{c}\text { AlmostAlways } \\
\text { N (\%) }\end{array}$} & \multirow{2}{*}{$\begin{array}{c}\text { AlmostNever } \\
\mathrm{N}(\%)\end{array}$} & \multirow{2}{*}{$\begin{array}{l}\text { Never } \\
\mathrm{N}(\%)\end{array}$} & \multicolumn{2}{|c|}{ Total } & \multirow{2}{*}{ Media } \\
\hline & & & & & $\mathbf{N}$ & $\%$ & \\
\hline Accessibility & $32(80)$ & $8(20)$ & $0(0)$ & $0(0)$ & 40 & 100 & 3.49 \\
\hline Interoperability & $39(98)$ & $1(2)$ & $0(0)$ & $0(0)$ & 40 & 100 & 3.80 \\
\hline Reuse & $33(83)$ & $6(15)$ & $1(3)$ & $0(0)$ & 40 & 100 & 3.59 \\
\hline
\end{tabular}

$\mathrm{N}=$ absolutefrequency / \% = relativefrequency

almost always (Table 1), obtaining an arithmetic average of 3.80 (suitable); this particularly corresponds with the mentioned by ${ }^{8}$, As Learning objects are independent of the medium through which are distributed and the knowledge management system, and can be used and transferred between different technologies and institutions.

With regard to the indicator reuse, it can be seen that the $83 \%$ of the teachers surveyed responded that they always the digital learning resources are reused in different educational contexts as often as they wish, while the $15 \%$ responded almost always and $3 \%$ almost never, for an arithmetic average of 3.59 (suitable); as, the reusability is the fundamental idea behind the learning objects, in which instructional designers build small components that can be reused in different educational contexts (math or other area of knowledge) as demonstrated in the present investigation $\frac{12}{}$.

\subsection{Components of the DLO}

Table 2 shows the distribution of frequencies of the indicators of the dimension components, particularly in regard to the Information Unit, $90 \%$ of the lecturers surveyed responded that they always the issuance of textual content using text editors is driven by the teacher, multimedia contents are stored in the database and the textual content is made in HTML format, while the $10 \%$ responded almost always, obtaining an arithmetic mean for this indicator of 3.67 (adequate); the above is compatible with the Highlight $\frac{13}{3}$, Who refer to the information units are formed by individual multimedia content (text, images, audio, video, among others), in which the user has the ability to generate textual content through access to text editors, both for plain text HTML format.

With regard to the indicator unit of content, the 95\% of subjects surveyed responded that they are always looking for the student to create your own templates, edit the content and store the results of their activities; only a $5 \%$ responded almost always, so as to obtain anarithmetic average of 3.77 (suitable); combining what was obtained with the theory ${ }^{14}$, Who claim that the content unit defines the location in which housed the contents of text, video and images, facilitating the generation of different composition templates considering the type of contents that the user want to use for each unit of content in particular; in addition, the environment in which focuses the content unit offers the user the possibility to generate their own templates of composition.

With regard to the indicator unit, $98 \%$ of respondents, responded that always the criteria for assessment of student are determined through the teaching unit in the ode, one can observe the standard of mathematics that is developing and the contents are designed to encourage work by students, both individually and collaboratively, while only $2 \%$ responded almost always, obtaining an arithmetic average of 3.66(adequate); the trend obtained corresponds to the theoretical postulates $\frac{15}{}$, Who argue that, following the principles of the meaningful learning, the didactic unit contains the topics, resources and teaching-learning activities and which are formed by units of content and other teaching units.

Table 2. Frequency distribution of the dimension components of the DLO

\begin{tabular}{|c|c|c|c|c|c|c|c|}
\hline \multirow{2}{*}{ Indicator } & \multirow{2}{*}{$\begin{array}{l}\text { Always } \\
\mathrm{N}(\%)\end{array}$} & \multirow{2}{*}{$\begin{array}{c}\text { AlmostAlways } \\
\mathrm{N}(\%) \\
\end{array}$} & \multirow{2}{*}{$\begin{array}{c}\text { AlmostNever } \\
\mathrm{N}(\%)\end{array}$} & \multirow{2}{*}{$\begin{array}{l}\text { Never } \\
\mathrm{N}(\%) \\
\end{array}$} & \multicolumn{2}{|c|}{ Total } & \multirow{2}{*}{ Media } \\
\hline & & & & & $\mathbf{N}$ & $\%$ & \\
\hline Unit of Information & $36(90)$ & $4(10)$ & $0(0)$ & $0(0)$ & 40 & 100 & 3.67 \\
\hline Content Unit & $38(95)$ & $2(5)$ & $0(0)$ & $0(0)$ & 40 & 100 & 3.77 \\
\hline DidacticUnit & $39(98)$ & $1(2)$ & $0(0)$ & $0(0)$ & 40 & 100 & 3.66 \\
\hline
\end{tabular}

$\mathrm{N}=$ absolutefrequency / \% = relativefrequency 
Table 3. Frequency distribution of the dimension types of DLO

\begin{tabular}{|c|c|c|c|c|c|c|c|}
\hline \multirow{2}{*}{ Indicator } & \multirow{2}{*}{$\begin{array}{l}\text { Always } \\
\text { N (\%) }\end{array}$} & \multirow{2}{*}{$\begin{array}{c}\text { AlmostAlways } \\
\mathrm{N}(\%)\end{array}$} & \multirow{2}{*}{$\begin{array}{c}\text { AlmostNever } \\
\mathbf{N}(\%)\end{array}$} & \multirow{2}{*}{$\begin{array}{l}\text { Never } \\
\text { N (\%) }\end{array}$} & \multicolumn{2}{|c|}{ Total } & \multirow{2}{*}{ Media } \\
\hline & & & & & $\mathbf{N}$ & $\%$ & \\
\hline Essential & $34(85)$ & $6(15)$ & $0(0)$ & $0(0)$ & 40 & 100 & 3.61 \\
\hline Closed Combination & $33(83)$ & $7(17)$ & $0(0)$ & $0(0)$ & 40 & 100 & 3.52 \\
\hline Open combination & $35(88)$ & $5(12)$ & $0(0)$ & $0(0)$ & 40 & 100 & 3.67 \\
\hline GenerativePresentation & $36(90)$ & $4(10)$ & $0(0)$ & $0(0)$ & 40 & 100 & 3.6 \\
\hline InstructionalGenerative & $27(68)$ & $10(25)$ & $3(7)$ & $0(0)$ & 40 & 100 & 3.33 \\
\hline
\end{tabular}

$\mathrm{N}=$ absolute frequency $/ \%=$ relative frequency

\subsection{Types of DLO}

Table 3 shows the distribution of frequencies of the indicators of the dimension types of DLO. With regard to the Fundamental indicator, $85 \%$ of respondents who always encourage the creation of documents on a single topic, digital resources are accessed in an individual manner in the ode and avoid combining the digital resource used, with other learning objects, while the $10 \%$ responded almost always perform this activity, for an average value of 3.61 (adequate). This trend corresponds to the theoretical postulates outlined that the OAfundamental rights are those that cannot be combined with other learning objects, since they are very general, being an individual digital resource, which is not combined with any other ${ }^{12}$.

With regard to the indicator combination closed, it can be seen that the $83 \%$ of subjects surveyed responded that they always the student combines digital resources, are accessed as a whole and the development of the topics within the learning object is suitable to the proposed educational level, while $17 \%$ responded almost always, with an average value of 3.52 (adequate); being this result relevant to the theory of who express that combination closed is a set of digital resources combined by the designer in the time of creation of the learning object, these digital resources cannot be accessed individually, but together $\frac{12}{2}$. An example of this is the video, in which you can access independently of the audio or video.

With regard to the indicator combination open, it was found that $88 \%$ of the subjects surveyed, responded that the contents are always up-to-date at the digital object, the digital resource is reused individually and is combined in response to the request of the student, being only a12\% responded almost always, representing an arithmetic mean according to the tabulation of 3.67 (adequate). The combination open area set of digital resourcesstatesby a computer in response to a request, although theycan also be reused individually; an example of this would be a web page whose content combines audio, video and text $\frac{12}{}$.

In the same veinforthe indicator, the generative presentation of the subjects $90 \%$ respondents always promote the reuse of digital resource in the context that you want to the student, the digital resource has a low extra-contextual and reusability is dominated in contexts for which was generated, the remaining $10 \%$ responded that almost always promotes this, obtaining an arithmetic mean for this variable of 3.60 (adequate); corresponding this with the theoretical postulates $\frac{12}{}$, Who review that a learning object of generative presentation has a high reusability intercontextual, this refers to the fact that can be used over and over again in similar contexts, they have a low extra reusability shortcut menu, and may not be used in systems for which they were not created.

The indicator Instructional Generative, showed an $68 \%$ of subjects surveyed responded that they always evaluate the student in their ability to remember a series of steps, use instructional strategies abstract and the digital resource is conceived by the student to perform a series of steps, while $25 \%$ responded almost always, and a $7 \%$ responded almost never (Table 3); there was an average of 3.33 (adequate). The theoretical postulates, indicate that this type of learning object is designed to assess the capacity of an apprentice to remember a series of steps, support abstract as instructional strategies, for example: how to characterize the water molecule, where in order for the student to acquire knowledge, you are presented with the theory of how these molecules are formed to identify through an image $\frac{12}{2}$.

\subsection{Integration of a Variable, Dimensions and Indicators}

In Figure 1 presents the arithmetic average of each dimension associated with the variable DLO, with these values representing the tendency of the same, product 


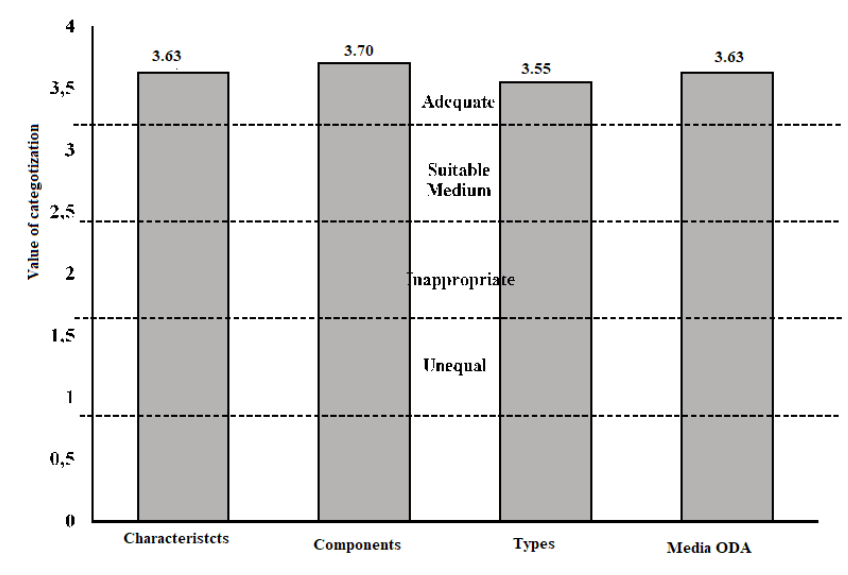

Figure 1. Categorization values of Dimensions (features, components, and types) and the Variable DLO. The dotted lines indicate the limits of scope of the different categories. Adec.: Suitable; Med. Adec.: Medium; Little Adec.: Inappropriate; Inadec.: inadequate.

of the responses obtained by the subjects of the study population. In this sense, the characteristics have the highest arithmetic with a value of 3.63 , placing it in the appropriate category, which allows the inference, that respondents recognize each of the components of this dimension. However, this trend corresponds to the theoretical concern that the DLO have certain characteristics that define and are agreed by the scientific community, which is to: accessibility, reusability and interoperability, finding these present in good measure in the educational institution studied?

It then presents the dimension Components, whose arithmetic mean has a value of 3.70 (Figure 1); which places within the scope of the appropriate category, which indicates that the respondents recognize each of the components of this dimension. As well, this trend corresponds to the theoretical postulates of those who refer to the components of the DLO, are shaped by a unit of information, content, didactics and technology, being its technology which contains the technological specifications and requirements. The minimum hardware and/or software to run the object ${ }^{5}$.

The dimension types, presented an arithmetic average of 3.55 (Figure 1); which is located in the area of category, which allows the inference, that respondents recognize the elements associated to this dimension. As a result, this trend corresponds to the theoretical postulates of who review that learning objects are categorized into fundamental, combination closed, open, generative and instructional generative presentation (12). Finally, the arithmetic mean for the variable DLO in its entirety, presented a value of 3.63; that the categorized in adequate; this indicates that respondents recognize each of the elements associated with the DLO, which are any digital resource that can be reused to support learning, inferring by this definition that any digital resource can be delivered through the network, whether big or small, corresponds to an $\mathrm{DLO} \stackrel{12}{ }$.

All of the components in its entirety are categorized as suitable, making the use of DLO in the educational institution "Denzil Escolar" from Riohacha, this taking place in a correct way, as well as displays a high level of characterization. However, there are ways to optimize the process by which applies this tool, since despite containing one or a few related ideas, can be useful to a context, but less for others. In this sense, the teacher must associate the objectives of the ode to one of the levels of cognitive domain of Bloom's taxonomy. The levels are classified as: complexity (knowledge, understanding and application) and greater complexity (analysis, synthesis and evaluation). Each of these domains indicates what the student is able to do; accordingly, it is possible to define the and how to teach, it is as well as it could set different ways to present the content of the DLO according to instructional objectives.

They can also accommodate some aspects according to its contents (data and concepts, procedures and processes, reflection, and attitudes), as well as didactic-curricular activities, are oriented toward the objectives (correctly formulated, feasibility) and content (information correct, accurate, non-discriminatory, of matter, structuring appropriate to the objectives and characteristics of students); as well as among other aspects to adapt could be the technician-aesthetic, where you will find the content readable, colours, size and appropriate resolution, screens is not recharged, etc. Once you have viewed the objects, these ratings should be included in the metadata information to guide your evaluation for future re-use.

Finally, with the strategy of functionality, the teacher will be able to know the operation of the DLO, in addition, is directed to the type of interaction, that is to say, active, expository, mixed, indefinite, speed, level of interaction, etc. related metadata are types of interactivity and level of interactivity; this added to a continuous assessment of the DLO, will allow the teacher to evaluate these objects from the perspective of the pedagogical aspects, that is, if you have areas of perfectly identified by their assessment 
indicators and meanings. In this way, you can determine whether the tool meets the instructional objectives focused on the evaluation of the student.

\section{Conclusions}

Digital Learning Objects have a structure (features, components, and types) and employment "adequate" in the educational institution "Denzil Escolar" from Riohacha, Colombia, and it became apparent that the teachers, a large percentage, recognize all the elements associated to them. Even so, it seeks to promote the use of these tools through the optimization of technological skills from a pedagogical viewpoint, which enable teachers to contribute much more to the improvement of the teaching and learning of mathematics by part of the student in this educational institution, and even projected this to all educational institutions in Colombia. Finally proposes the use of this instrument to assess and track, to the use of DLO in educational institutions in Colombia, in order to assist the process of optimizing the processes of teaching and learning not only of mathematics, but also from other contexts and subjects.

\section{Acknowledgments}

Author thanks the various areas of the educational institution "Denzil School" in the city of Riohacha for 'willingness to work together' to carry out this research.

\section{References}

1. García M, Arzuaga R. Explorando, desde una perspectiva inclusiva, el uso de las TIC para atender a la diversidad. Profesorado Revista Currículum Formación Profesorado. 2012 de abril de 19; 16(1):18.

2. Alva de la Selva A. Los nuevos rostros de la desigualdad en el siglo xxi: la brecha digital. Revista Mexicana de Ciencias Políticas y Sociales. 2015; 60(223):265-85. https://doi. org/10.1016/S0185-1918(15)72138-0

3. Pérez J, Grau M. La ense-anza de la geometría asistida por computadoras: una nueva realidad en la secundaria básica. Didáctica y Educación. 2010; (3):47-62.
4. Rumiguano K. Factores de éxito desde la perspectiva asociativa que influye en el Programa Hilando el Desarrollo de la Economía Social y Solidaria. Universidad Técnica de Ambato. Facultad de Contabilidad y Auditoría; 2016.

5. Alles M. Comportamiento organizacional: Cómo lograr un cambio cultural a través de Gestión por competencias. Santa Marta: Ediciones Granica; 2013. p. 1-536.

6. Rodríguez L. Como las Prácticas docentes inciden en el uso de las TIC como herramienta en el proceso ense-anza y aprendizaje en las aulas de primaria de la escuela Albert Einstein durante el ciclo escolar agosto- diciembre 2015. DSpace Repository; 2015.

7. Troncoso O, Cuicas M, Debel E. El modelo B-Learning aplicado a la ense-anza del curso de matemática I en la carrera de ingeniería civil. Revista Electrónica Actualidades Investigativas en Educación. 2010; 10(3).

8. Ros MZ. Secuencias de contenidos. Especificaciones para la secuenciación instruccional de objetos de aprendizaje. Universidad de Alcalá; 2010.

9. Tobón ST, Pimienta Prieto JH, García Fraile JA, Morales Veyra GC, Martínez Amigón CC. Secuencias didácticas: Aprendizaje y evaluación de competencias. México: Pearson Educación de México, S. A. de C. V; 2010. p. 1-217.

10. Quiroz J. Dise-o y moderación de Entornos Virtuales de Aprendizaje (EVA). Editorial UOC; 2011. p. 1-166.

11. Hernández R, Fernández C, Baptista P. Metodología de la Investigación. México: Mc Graw Hill; 2014.

12. Zapata-Ros M. Teorías y modelos sobre el aprendizaje en entornos conectados y ubicuos. Bases para un nuevo modelo teórico a partir de una visión crítica del "conectivismo". Education in the Knowledge Society. 2015; 16(1):69-102. https://doi.org/10.14201/eks201516169102

13. Almenara JC. Tendencias para el aprendizaje digital: de los contenidos cerrados al dise-o de materiales centrado en las actividades. El Proyecto Dipro 2.0. RED. Revista de educación a distancia. 2012; (32):1-20.

14. Cabero-Almenara J. Los retos de la integración de las TICs en los procesos educativos: Límites y posibilidades. Perspectives in Education. 2010; 49(1):32-61.

15. Galvis ÁWS, Perilla MCC, Morales DL. Estrategias y ense-anza-aprendizaje de la lectura. Rev Folios. 2017; (26):27-38. 